\title{
THE ATMOSPHERIC IMPACT OF SASOL SYNFUELS OPERATIONS ON ADJACENT RESIDENTIAL DEVELOPMENT
}

\author{
O.J. Pretorius \\ Sasol Synfuels Environment, Private Bag X1000, Secunda 2302 \\ J.O. Okonkwo, Tshwane University of Technology
}

\begin{abstract}
Sasol Synfuels is a petrochemical industry producing fuels and chemicals from coal and situated in the Gert Sibande district municipality of Mpumalanga.

These activities result in pollutants being released into the atmosphere. It was required to determine if reducing the radius of a $5.2 \mathrm{~km}$ pollution circle, measured from the centre of the plant, by $400 \mathrm{~m}$, to allow further residential development, will expose residents to an unacceptable ambient benzene concentration. A detailed study was implemented whereby the ambient air was sampled and analysised during a two seasonal period to determine how the benzene emissions released from the factory will impact on future residents within this $400 \mathrm{~m}$ area. Meteorological measurements were also used to monitor atmospheric conditions.
\end{abstract}

The results showed that the yearly average of ambient benzene concentrations for Secunda was $0.41 \mathrm{ppb}$ and $0.64 \mathrm{ppb}$ for eMbalenhle which was below the South African standard, but there were frequent sampling periods when the short-term concentrations exceeded the annual standard, occurring mostly during the night, when the majority of residents were at home.

From the results obtained, the $5.2 \mathrm{~km}$ pollution circle should therefore be maintained to ensure this risk of exposure to people is kept to a minimum.

\section{INTRODUCTION}

Sasol Synfuels, a company that produces synthetic fuels from coal, covers an area of more than $13 \mathrm{~km}^{2}$ and is designed for a Coal to Liquid (CTL) process. Here value is added to 40.5 million tons per annum, of low-grade coal from the surrounding Sasol coal mines Gasification of the coal followed by further processes produces fuels such as diesel, petrol, aviation fuel and liquid petroleum gas (LPG). The process also produces chemical feedstocks such as alpha olefins to be used in the plastic industry. Due to the immense scale, complexity and diversity of the Sasol Synfuels operations, emissions of carbon monoxide, sulphur dioxide, nitrogen dioxide, hydrogen sulphide and volatile organic compounds are released into the atmosphere. As Sasol is aware of the impacts these emissions have on the surrounding areas, they require new technology, systems and skills to reduce and where possible eliminate the impacts.

In order to limit the impact of these emissions on people residing in the surrounding residential areas a pollution circle, with a radius of $5.2 \mathrm{~km}$, measured from the centre of Sasol Synfuels plant, was demarcated in terms of the Atmospheric Pollution Prevention Act when the plants were built in the late 1970 "s. Within this circle, no residential development is allowed, but commercial and indistrial developments can take place (small businesses).

\section{Problem statement}

With the initial "calculation" of the pollution circle in 1978 (there is a possibility that a dispersion model was used for this calculation), no documented information, such as meteorological parameters and point source emissions (the plant design was new, the impact on the ambient air was unknown at this stage) were available. This meant that the circle radius was based on assumed information and not on rigorous scientific analysis. Sasol Synfuels Environment decided to implement a research program which will scientifically determine if this radius of $5.2 \mathrm{~km}$ is sufficient or excessive in limiting the impact on residents. 
This research program would be based on the measurement of benzene in the surrounding ambient air, as it was a known point source emission from the plants' operations and the concentration levels have been recorded.

\section{Characteristics of Benzene}

The proposed South African National Standard (SANS) states that benzene is a human genotoxic carcinogen and there is no identifiable threshold levels below which there is no risk to human health. However the limiting value for benzene as given in the standard is difficult to achieve because of sitespecific dispersion characteristics or relevant climatic conditions. If the application of the measures can result in severe socio-economic problems, provincial and local authorities may ask for area time-limited extension under specific conditions. The proposed annual limit value for the protection of human health, averaged over a calendar year is $5 \mu \mathrm{g} / \mathrm{m}^{3}(1.6 \mathrm{ppb})$. This SANS document also indicates that the reference methods for the sampling and analysis of benzene are either USEPA Compendium method TO-14A or method TO-17. (SANS 1929, 2005:12).

\section{Benzene}

Benzene is a widely used chemical, as a constituent in motor fuels, as a solvent for fats, waxes, resin, paints, plastics and rubber. It is also used in the manufacturing of detergents, explosives and pharmaceuticals. Natural sources of benzene include volcanoes and forest fires. Individuals employed in industries that manufacture or use benzene may be exposed to the highest levels of benzene. It is also present naturally in petrol and mobile (vehicular) emissions are a major source of benzene in ambient air, however, there are also significant industrial sources such as oil refineries (USA Department of Labour, 2006).

\section{Benzene toxicity}

The United States Environmental Protection Agency (USEPA, 2002) has classified benzene as a group A known human carcinogen. It must be remembered that there may be no safe level of exposure to a carcinogen, so all contact should be reduced to the lowest possible level.
The United States Environmental Protection Agency (EPA) provides unit risk factors for benzene. Recalculated as lifetime risk, the EPA estimates that, if an individual were to continuously breathe air containing benzene at an average concentration of between $0,04-0,14 \mathrm{ppb}$ over a 70 year lifetime, the person would theoretically have no more than onein-a-million increased probability of developing cancer as a direct result. As the probabilty is directly linked to concentration, EPA estimates that, if an individual were to continuously breathe air containing benzene at an average concentration of between $0,4-1,4 \mathrm{ppb}$ over a 70 year lifetime, the person would theoretically have no more than onein-a-hundred thousand increased probability of developing cancer as a direct result of continuously breathing air containing this chemical and at an average concentration of between $4,0-14 \mathrm{ppb}$ over a 70 year lifetime, the probability would increase to one in a ten thousand.(ATSDR, 1997:4; USEPA, 2002:3).

\section{METHODS AND MATERIALS}

\section{Introduction}

Monitoring sites were identified in the surrounding residential areas of Secunda and eMbalenhle, it was at these points that sampling was carried out over a period of 18 months to include two seasonal periods These sites had to have easy access, be secure from unauthorised entry and far from any obstructions that may affect the wind profile. The measurements were also used in combination with wind speed and wind direction data to determine the dispersion of emitted hydrocarbons from the plant and therefore the risk to human health.

\section{Study Area}

The pollution circle as shown in Figure 1 indicates the area of the $5.2 \mathrm{~km}$ pollution zone. Sample points were located at Secunda, co-ordinates $26^{\circ} 31.40^{\prime \prime} \mathrm{S}$, $29^{\circ} 11.38^{\prime \prime} \mathrm{E}$, which is situated $\pm 4.7 \mathrm{~km}$ to the North of the factory and eMbalenhle, co-ordinates $26^{\circ} 33.10^{\prime \prime} \mathrm{S}, 29^{\circ} 06.15^{\prime \prime} \mathrm{E}$, which is situated $\pm 4.8 \mathrm{~km}$ to the West of the factory. The measurements would be taken to the North (Secunda residential area) and to the West (eMbalenhle residential area) of the plant Placement of the canisters depended on the wind 
direction, so sampling was only done if the wind was blowing in the direction of the measurement points; this is the reason for the limited number of results obtained for Secunda $(4.7 \mathrm{~km})$. As a result of the winter prevailing wind direction, North East/ South East, it was possible to sample more often at eMbalenhle (4.8 km).

\section{Materials}

The study used two types of instrumentation, determining the extent of resident's exposure to toxic pollutants, if living at a distance of $4.8 \mathrm{~km}$ from the plant activities.

\section{Equipment used was:}

- Toxic Organic (T.O.) canister (under vacuum), sampling for a 24 hour period, after which the air sample was analysised by the North West University Department of Chemistry using a GC-MS instrument.

- Ambient air gas chromatograph with flame ionisation detection (FID) and on-line sample preparation, for the analysis of volatile organic compounds (VOC) $\mathrm{C}_{2}-\mathrm{C}_{12}$ in the atmosphere.

Figure 2 shows that when the Toxic Organic (T.O.) Canisters were placed at a distance of $4.7 \mathrm{~km}$ (Secunda) and $4.8 \mathrm{~km}$ (eMbalenhle), there were two exceedenances of the benzene standard at eMbalenhle and one exceedenance at Secunda. The average ambient benzene levels recorded during the sampling period was $\pm 1.0 \mathrm{ppb} / 3.1 \mu \mathrm{g} / \mathrm{Nm}^{3}$. Canisters were only placed at the monitoring points

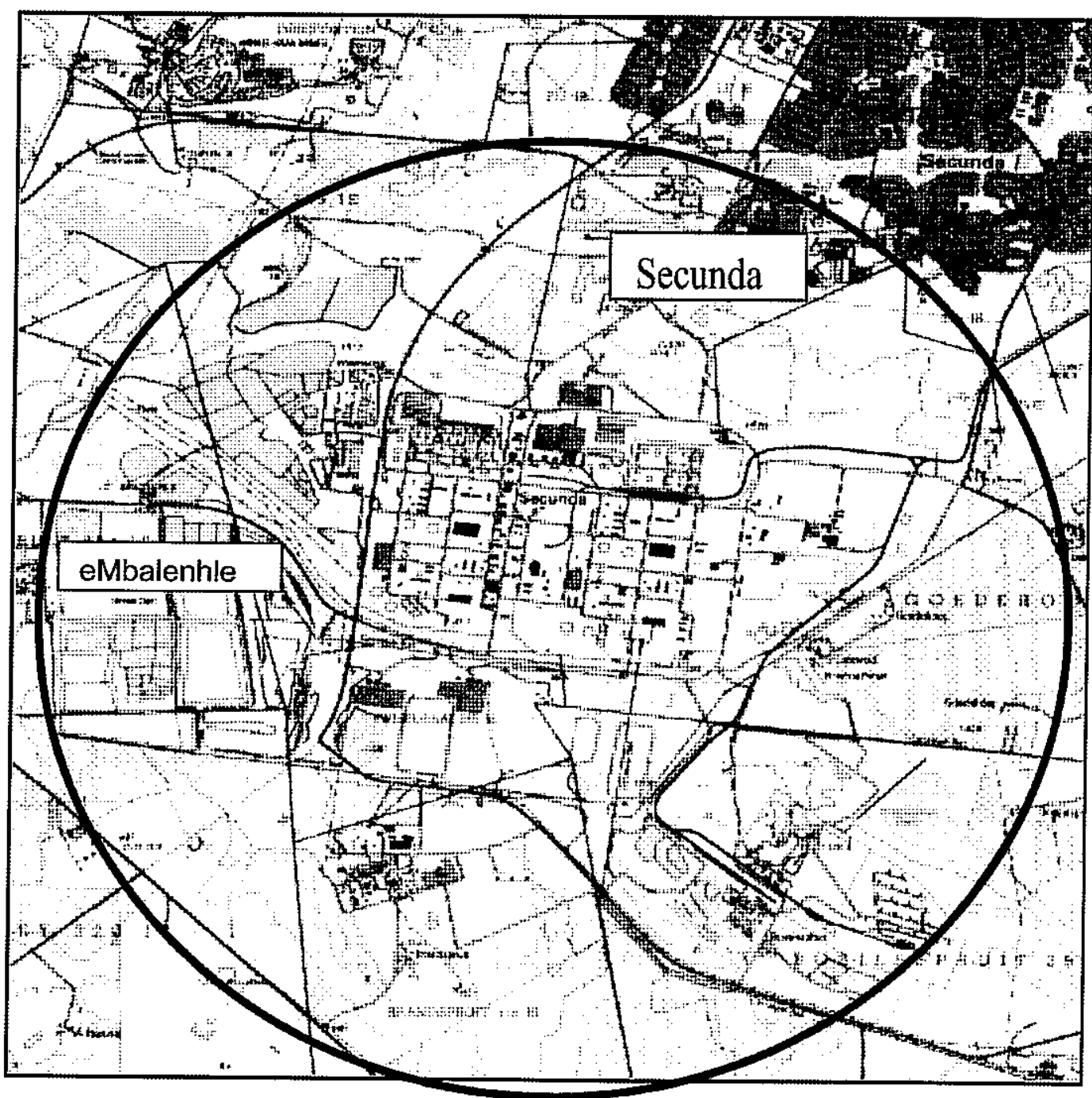

Figure 1: Map of study area.

Figure 1 shows the study area of the research project as well as the position of the two sampling points 
Results and Discussions

Toxic Organic (T.O.) canister results



Figure 2: Results of residential areas ambient benzene concentration, sampling with T.O. Canisters over a 24 hour period.

when the wind was blowing in the direction of these points.

\section{Ambient gas chromatograph results (AIROMOZONE)}

Figures 3 and 4, show the continuous ambient benzene concentrations for the summer months. These samples were taken every 30 minutes. When comparing the Secunda results with the eMbalenhle results, it can be seen that a larger number of benzene exceendences $(>1.6 \mathrm{ppb})$ were recorded in eMbalenhle than in Secunda. This can mainly be attributed to the higher percentage of time that the wind blew in this direction).

The average ambient temperatures are displayed in each graph (on next page). With the higher temperatures recorded during the summer months (January) it should be expected that high benzene concentrations would be recorded (vapour emissions from waste product dams). This trend was not observed during the research period and can be attributed to the high atmospheric instability associated with summer periods resulting in better dispersion actions.

\section{Benzene impact due to meteorological conditions}

The data recorded for the three parameters, shows that wind direction, coupled with stable atmospheric conditions, during the evenings (inversion), were the deciding factors, which resulted in peak benzene levels being recorded at the monitoring positions. In Figures 5 and 6 a number of days were selected, where the hourly wind direction is displayed in graphs to demonstrate how it affects the benzene levels recorded in the Secunda and eMbalenhle residential areas.

As eMbalenhle monitoring site is situated to the South West of the plant any winds blowing from a direction of between 30 line and 75 line degrees, gives an indication of the impact plant operations has on the residential areas air quality. Using these boundaries the graph in Figure 5 indicates that as soon as the wind direction falls within this $\mathbf{3 0}$ and 


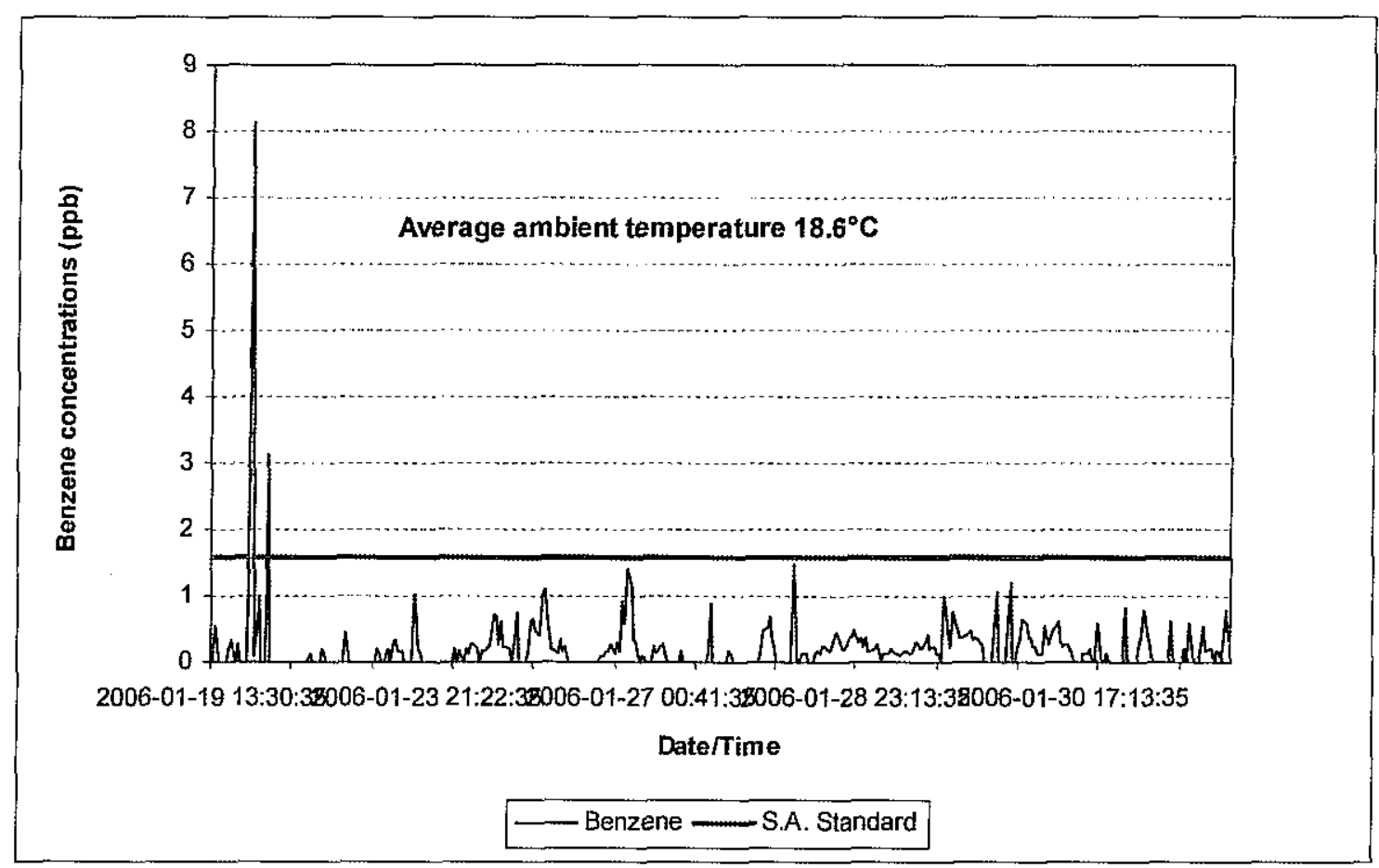

Figure 3: Ambient benzene concentrations in the Secunda Residential area, during January 2006, using online ambient GC.

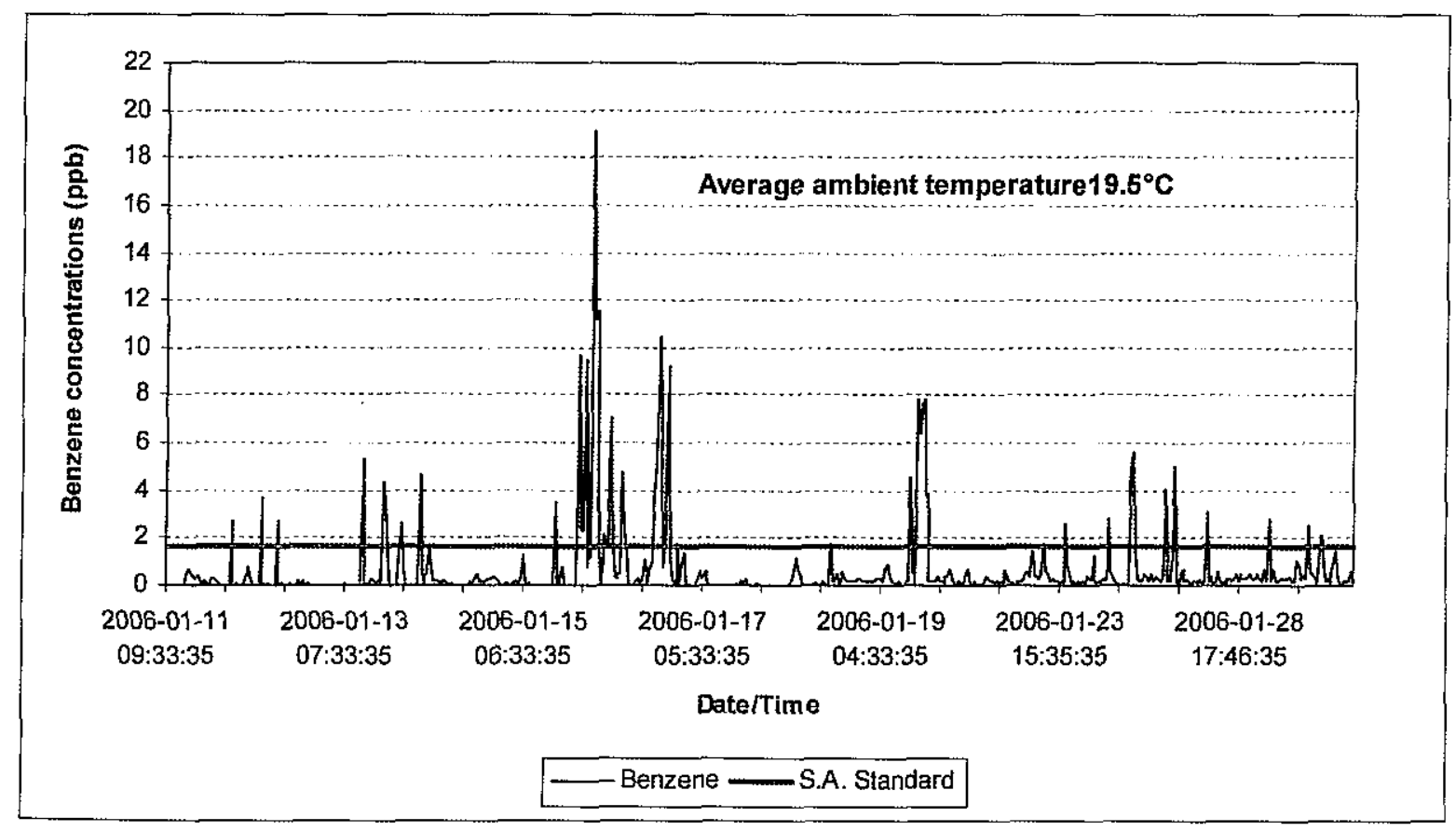

Figure 4: Ambient benzene concentration eMbalenhle residential area January 2006, using on-line ambient GC. 
75 degree limit, high benzene levels are recorded. Any other time that the wind direction was outside these limits, low benzene concentrations were recorded. The results showed that $18 \%$ of the 30 minute benzene readings, recorded for the 24 hour period, exceeded the proposed South African Standard of $1.6 \mathrm{ppb}$. The arrows indicate these exceedenances occurred mostly during the evenings, possibly due to stable atmospheric conditions. The wind speed recorded for the same time period is also displayed on the graph.

As the Club monitoring site is situated to the North East of the plant any wind blowing from a direction of between 200 line and 240 line degrees, gives an indication of the impact the plant operations has on the residential areas air quality.

Using these boundaries the graph in Figure 6 indicates that as soon as the wind direction falls within this 200 and 240 degree limit, high benzene levels are recorded. Any other time that the wind direction was outside these limits, low benzene concentrations were recorded. The results showed that $22 \%$ of the 30 minute benzene readings, recorded for the 24 hour period, exceeded the proposed South African Standard of $1.6 \mathrm{ppb}$. The arrows indicate these exceedenances occurred mostly during the evenings, possibly also due to stable atmospheric conditions. The wind speed recorded for the same time period is also displayed on the graph.

From the above results it can be seen that wind direction and stable atmospheric conditions, during the evenings, are the dominating factors which determines whether or not high benzene levels are measured in the residential areas.

\section{Conclusions}

From information documented and evaluated in the research project, it is seen that there are frequent time periods, when the ambient benzene concentrations exceeded the proposed South African Standard of $1.6 \mathrm{ppb}$ (yearly average). The data also shows that the yearly average for ambient benzene concentrations, during the research period (end of September 2006), for Secunda was $0.41 \mathrm{ppb}$ and 0.64 $\mathrm{ppb}$ for eMbalenhle, which is below the South African standard.

The main concern is the number of time periods when there are exceedences, these mostly occur during the night, usually from $18 \mathrm{~h} 00$ until $06 \mathrm{~h} 00$. This means that when the majority of people are in

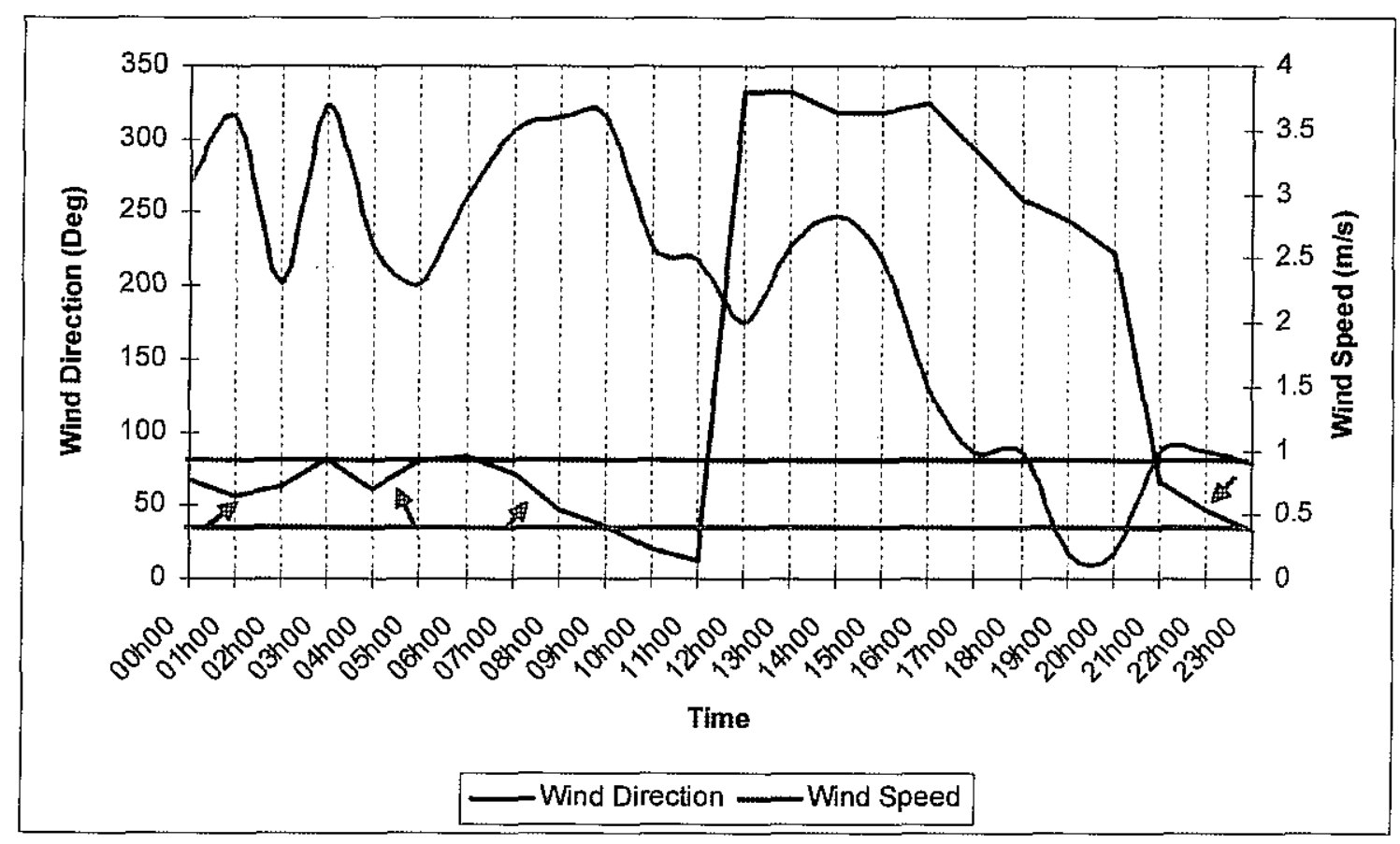

Figure 5: Hourly wind direction eMbalenhle 14 February 2006 


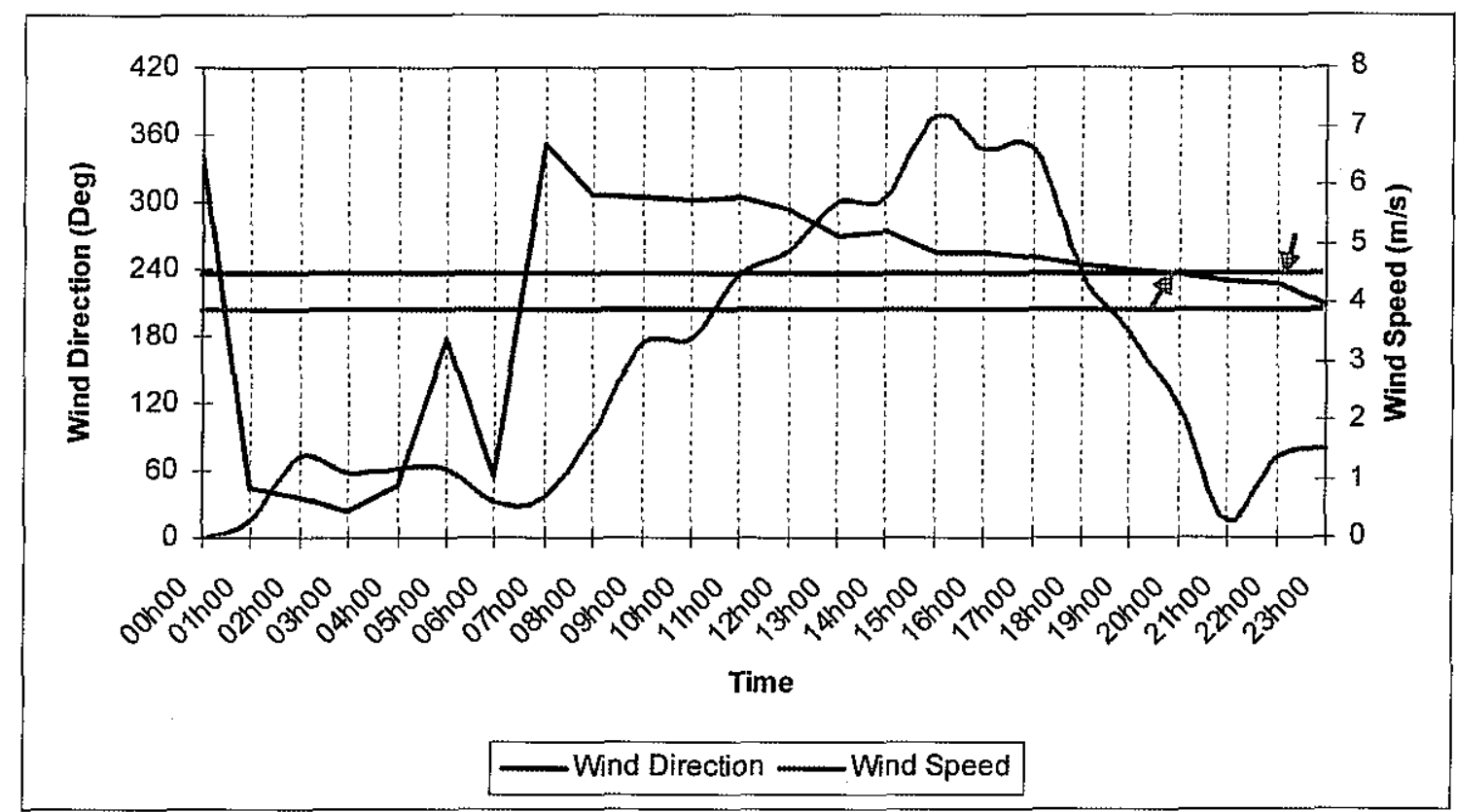

Figure 6: Hourly wind direction Secunda 12 March 2006

their homes they are being exposed to high benzene concentrations. As benzene is classified as a Group A known human carcinogen there may be no safe level of exposure to a carcinogen, so all contact should be reduced to the lowest possible level.

The $5.2 \mathrm{~km}$ radius circle should therefore be maintained to ensure this risk of exposure to people is kept to a minimum

\section{BIBLIOGRAPHY}

AGENCY FOR TOXIC SUBSTANCES AND DISEASES REGISTRY (ATSDR). 1997. Toxicological profile for Benzene. Atlanta: Division of Toxicology.

AGENCY FOR TOXIC SUBSTANCES AND DISEASES REGISTRY (ATSDR). 2006. ToxFAQfor benzene. Atlanta: Division of Toxicology.

CHROMATO-SUD. 2005. Airmozone User's Manual, Edition: April 2004. France, Bordeaux: Cromato-Sud.

RESTEK TECHNICAL GUIDE. 2005. A guide to passive air sampling, equipment needed and practical techniques for collecting air samples. Restek
Corporation: Restek U.S.

SOUTH AFRICAN NATIONAL STANDARD, SANS: 1929. 2004. Ambient Air Quality - limits for common pollutants, EDITION 1 Pretoria: South African Bureau of Standards.

UNITED STATES DEPARTMENT OF LABOUR OCCUPATIONAL SAFETY \& HEALTH ADMINISTRATION. 2006. Benzene hazard recognition. United States: Washington.

UNITED STATES ENVIRONMENTAL PROTECTION AGENCY. 2002. Integrated Risk Information System (IRIS) on benzene. Washington, DC: National Centre for Environmental Assessment, Offices of Research and development.

UNITED STATES ENVIRONMENTAL PROTECTION AGENCY. 1999. Compendium Method TO$14 A$, Determination of Volatile Organic Compounds (VOCs) in ambient air using specially prepared canisters with subsequent analysis by gas chromatography. Center for Environmental Research Information, Office of Research and Development, 